\title{
Spectral effects and determining the solar spectral distribution for Mugla and Ankara
}

\author{
Murat Kabakcı, Rustu Eke \\ Department of Physics, Mugla Sitki Kocman University, Turkey
}

\begin{tabular}{l} 
Article Info \\
\hline Article history: \\
Received Dec 13, 2019 \\
Revised Feb 19, 2020 \\
Accepted Oct 14, 2020 \\
\hline
\end{tabular}

\section{Keywords:}

Modelling

Solar energy

Solar radiation

SPCTRL 2

Spectral distribution

\begin{abstract}
Not only is the theoretical calculation of the amount of solar radiation but also the characteristics of the light so significant in deciding the spectral sensitivity of the PV modules. The amount of radiation reaching on the earth depends on many atmospheric parameters such as wavelength and air mass. Spectral 2 is a model that calculates the amount of radiation for any region depending on the wavelength and atmospheric parameters. There are no theoretical and experimental studies on this subject in Turkey until now. In this study, the amounts of radiation coming to the surface having horizontal and different tilt angles were calculated for Mugla and Ankara. Due to the different climatic characteristics of Mugla and Ankara, the amount of radiation varies. According to the results, in winter and autumn, the amount of radiation which comes to Ankara and Mugla, is different each other. Due to the different climatical and geographical characteristics of Mugla and Ankara, the amount of radiation varies. The model, which is used in this study, due to atmospheric effects that have, is more comprehensive than any other empirical models made in Turkey.
\end{abstract}

This is an open access article under the CC BY-SA license.

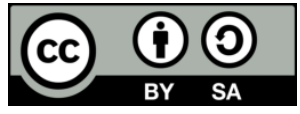

\section{Corresponding Author:}

Murat Kabkaci

Department of Physics

Mugla Sitki Kocman University

48000 Kötekli/Muğla, Turkey

Email: mrtkbkc@gmail.com

\section{INTRODUCTION}

The sun is the world's largest source of energy. Calculating the amount of radiation from the sun is very important in photovoltaic applications. Sunlight is a form of electromagnetic radiation. Electromagnetic radiation from sun ranging from $0.25 \mu \mathrm{m}$ to $4.5 \mu \mathrm{m}$ in wavelength and has three different regions. These regions are named as ultraviolet rays (UV), visible, and infrared (IR). Sun's radiant power is the solar irradiance power in per unit area in $\mathrm{W} / \mathrm{m}^{2}$ or $\mathrm{kW} / \mathrm{m}^{2}$ [1]. Solar radiation is reduced because of atmospheric conditions like scattering, reflection, and absorption. Particles which are in the atmosphere cause scattering. Also, water vapour, in the atmosphere, causes absorption [2, 3]. Clouds are the main effect of diffused irradiance. Reflection occurs as a result of solar radiation hitting a reflective surface. Latitude of the location, day (time in the year) is the other parameters which affect the incident solar radiation. The amount of solar radiation come to the surface can be calculated using different models. But the effect of the wavelength variation on the output is not analysed or calculated in detail. Only small-scale solar cells are used with different materials. In our study, we used SPCTRL 2 calculating program which allows calculating spectral irradiance depending to wavelength for desired location will be discussed. The amount of beam, scattered, and global radiation coming to a horizontal and inclined surface in Mugla and Ankara was calculated using 
the SPCTRL 2 model. Here, the factors affecting the amount of radiation incident on the surface were investigated.

\section{RESEARCH METHOD}

\subsection{Basic terms of solar irradiance}

The amount of radiation coming to the outer surface of the atmosphere varies throughout the year due to the change in the distance between the earth and the sun [4]. Solar radiation reaching the surface; It depends on parameters such as location, atmospheric conditions, aerosol, state of the ozone layer, time of day, distance from the earth/sun. And also, it varies with wavelength which is so called spectra. The amount of radiation that reaches the surface varies depending on the wavelength. Studying this change is very important for theoretical calculations. The most commonly used spectrum is those published by The Committee Internationale d'Eclaraige (CIE) and given in Figure 1. Solar energy is named by different names, especially density and radiation. In photovoltaic applications, the terms radiation and density are preferred [5]. The amount of energy is usually expressed in units of $\mathrm{mW} / \mathrm{cm}^{2}$ or $\mathrm{W} / \mathrm{m}^{2}[6]$.

\section{Solar Radiation Spectrum}

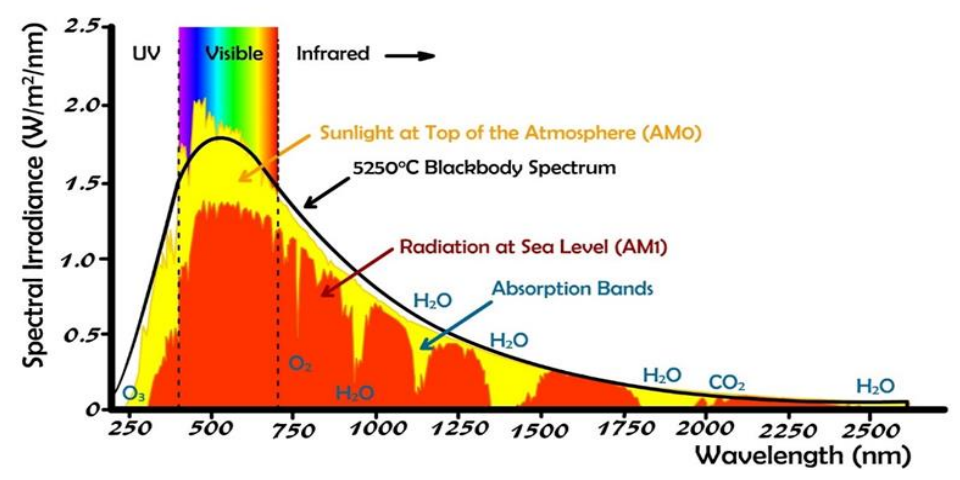

Figure. 1. Atmospheric effects on global irradiance

In addition to knowing the graph of the incident radiation depending on the wavelength, the amount of energy for each wavelength must also be known. Thus, a better understanding of the spectral sensitivity of the solar cell in photovoltaic applications is provided. So, there are many studies all over the world reports the performance of different types of solar cells depend on their technologies [7,8]. The relative spectral responsivity for several technologies is plotted in Figure 2 where the spectral responsivity is the sensitivity of the device or solar cell to optical radiation of different wavelengths.

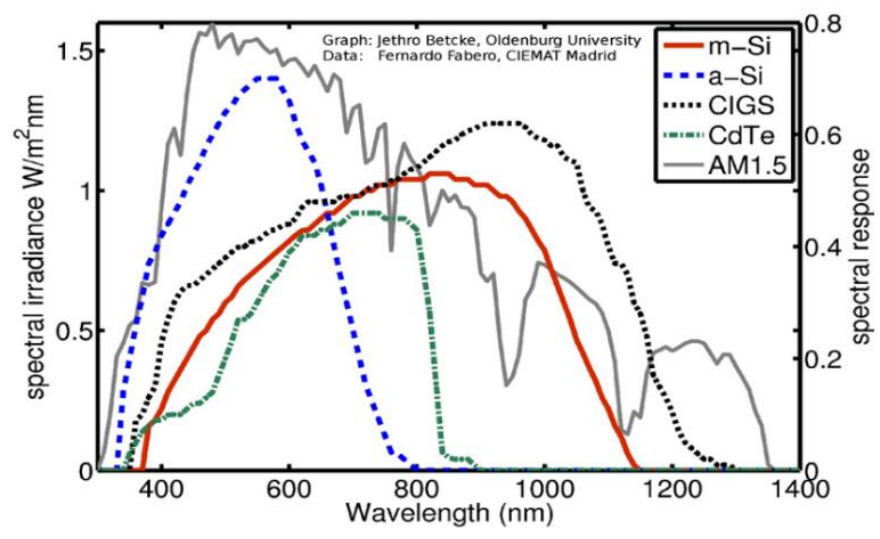

Figure. 2. Relative spectral responsivity of seven PV technologies [9] 
Solar constant is the solar radiation on per unit surface (in $\mathrm{m}^{2}$ ) at the earth's outer atmosphere, oriented normal to the sun's rays and its value is $1.367 \mathrm{~W} / \mathrm{m}^{2}$. Air mass is an indication of the distribution of sunlight within the atmosphere and is calculated as,

$$
\operatorname{Air} \operatorname{Mass}(A M)=\frac{1}{\cos (\theta)}
$$

where $\theta$ is the incidence angle of sun rays. The amount of solar radiation in the atmosphere varies due to different atmospheric effects [10].

\subsection{Simple spectral model on global irradiance}

In this model, the variation of the amount of total solar radiation into the atmosphere depending on the wavelength is modelled by atmospheric effects. Researchers may obtain the capability to produce accurate terrestrial spectra using only a computer [11]. For wavelength $\lambda$ and at ground level direct normal irradiance (DNI) on a surface normal to the direction of the sun as

$$
I I_{d \lambda}=H_{0 \lambda} \cdot D \cdot T_{r \lambda} \cdot T_{a \lambda} \cdot T_{w \lambda} \cdot T_{o \lambda} \cdot T_{u \lambda}
$$

$\mathrm{H}_{0 \lambda}$ is the extra-terrestrial irradiance depending on wavelength $\lambda$; $\mathrm{D}$ is the effect of the earth-sun distance; and $\mathrm{T}_{\mathrm{r} \lambda}, T_{a \lambda}, \mathrm{T}_{\mathrm{w} \lambda}, \mathrm{T}_{\mathrm{o} \lambda}$ and $\mathrm{T}_{\mathrm{u} \lambda}$ are the transmittance functions of the atmosphere depending on wavelength. $\mathrm{T}_{\mathrm{r} \lambda}$ Rayleigh scattering, $T_{a \lambda}$ aerosol attenuation [12], $T_{w \lambda}$ water vapour absorption [13], $T_{\mathrm{o} \lambda}$ ozone absorption [14], and $\mathrm{T}_{\mathrm{u} \lambda}$ uniformly mixed gas absorption, respectively. Here $\mathrm{D}$ is given as [15]:

$$
D=1,00011+0,034221 \cdot \cos (\varphi)+0,00128 \cdot \sin (\varphi)+0,000719 \cdot \cos (2 \varphi)+0,000077 \cdot \sin (2 \varphi)
$$

The day angle $\varphi$ is given;

$$
\varphi=2 \pi \frac{d-1}{365}
$$

where $d$ is the day number of a year. Rayleigh scattering parameter $\left(T_{r}\right)$ is given,

$$
T_{r \lambda}=\exp \left\{\frac{-M^{\prime}}{\lambda^{4} \cdot\left(115,6406-\frac{1,335}{\lambda^{2}}\right.}\right\}
$$

$\mathrm{M}^{\prime}$ is the pressure-corrected air mass. Relative air mass as given by;

$$
M=\left[\cos (Z)+0,15(93,885-Z)^{-1,253}\right]^{-1}
$$

$Z$ is apparent solar zenith angle.

$$
M^{\prime}=\frac{M \cdot P}{P_{0}}
$$

$P_{0}=1013 \mathrm{mb}$ and $P$ is measured surface pressure. Aerosol scattering and absorption $\left(T_{a \lambda}\right)$ is;

$$
\begin{aligned}
& T_{a \lambda}=\exp \left\{-\beta_{n} \lambda^{-a_{n}} M\right\} \\
& \alpha_{1}=1,2074 \text { for } \lambda<0,5 \mu m \\
& \alpha_{2}=1,2060 \text { for } \lambda>0,5 \mu m
\end{aligned}
$$

Water vapour absorption $\left(\mathrm{T}_{\mathrm{w} \lambda}\right)$ is;

$$
T_{w \lambda}=\exp \left\{\frac{-0,2385 \cdot a_{w \lambda} \cdot W \cdot M}{\left(1+20,07 \cdot a_{w \lambda} \cdot W \cdot M\right)^{0,45}}\right\}
$$

here $\alpha_{W \lambda}$ is the water vapour absorption coefficient as a wavelength $\lambda$ and $\mathrm{W}$ is the precipitable water vapour $(\mathrm{cm})$ in a vertical path [16]. It is difficult to calculate the amount of indirect radiation with a mathematical model for any surface. In this model, different simple formulations are used for producing spectra on inclined surfaces [17]. For a horizontal surface, there are three components of indirect radiation. First is the Rayleigh 
scattering component $I_{r} \lambda$, second is the aerosol scattering component $I_{a} \lambda$, last one is the component that accounts for multiple reflection of irradiance between the ground and the air $\mathrm{I}_{\mathrm{g} \lambda}$ [18]. The total scattered irradiance, $\mathrm{I}_{\mathrm{s}} \lambda$, is then given as,

$$
I_{s \lambda}=I_{r \lambda}+I_{a \lambda}+I_{g \lambda}
$$

These components can be calculated independent of each other. The spectral global irradiance on an inclined surface is represented as [19, 20]:

$$
\begin{aligned}
I_{T \lambda}(t)= & I_{d \lambda} \cdot \cos (\theta)+I_{s \lambda}\left[\left(\frac{I_{d \lambda} \cdot \cos (\theta)}{H_{0 \lambda} \cdot D \cdot \cos (Z)}\right)+0,5 \cdot(1+\cos (t)) \cdot\left(\frac{1-I_{d \lambda}}{H_{0 \lambda} \cdot D}\right)\right] \\
& +0,5 \cdot I_{T \lambda} \cdot r_{g \lambda \cdot}(1-\cos (t))
\end{aligned}
$$

where $\theta$ is the tilted surface incidence angle of the direct beam and tilt angle of the inclined surface is t. The tilt angle is zero for a horizontal surface and $90^{\circ}$ for a vertical surface. The spectral global irradiance on a horizontal surface is represented as [21-28]:

$$
I_{T \lambda}=I_{d \lambda} \cdot \cos (Z)+I_{S \lambda}
$$

Spectral irradiance is calculated for horizontal and $30^{\circ}$ tilt angle with SPECTRAL2. Calculations were made for the Muğla and Ankara province and one month was chosen to represent every season. Due to its different geographical characteristics, the variation of the amount of radiation coming to Muğla and Ankara has been investigated depending on wavelength. Ankara is the capital and $2^{\text {nd }}$ big city of Turkey with over 5.5 million populations. The annual solar irradiation per square meter is calculated as $1500 \mathrm{kWh} / \mathrm{m}^{2}$ year and the location in Turkey is given in Figure 3. Muğla is located at the south west corner of Turkey. It is one of the important cities of the country in tourism with over $1650 \mathrm{kWh} / \mathrm{m}^{2}$-year annual solar insolation and this is also given in Figure 3 in colour range with its location. Although the area under spectral irradiancewavelength curve gives the total solar irradiance solar output of photovoltaic modules varies with their materials as defined in Figure 2. Some atmospheric parameters for Muğla and Ankara are given in Table 1.

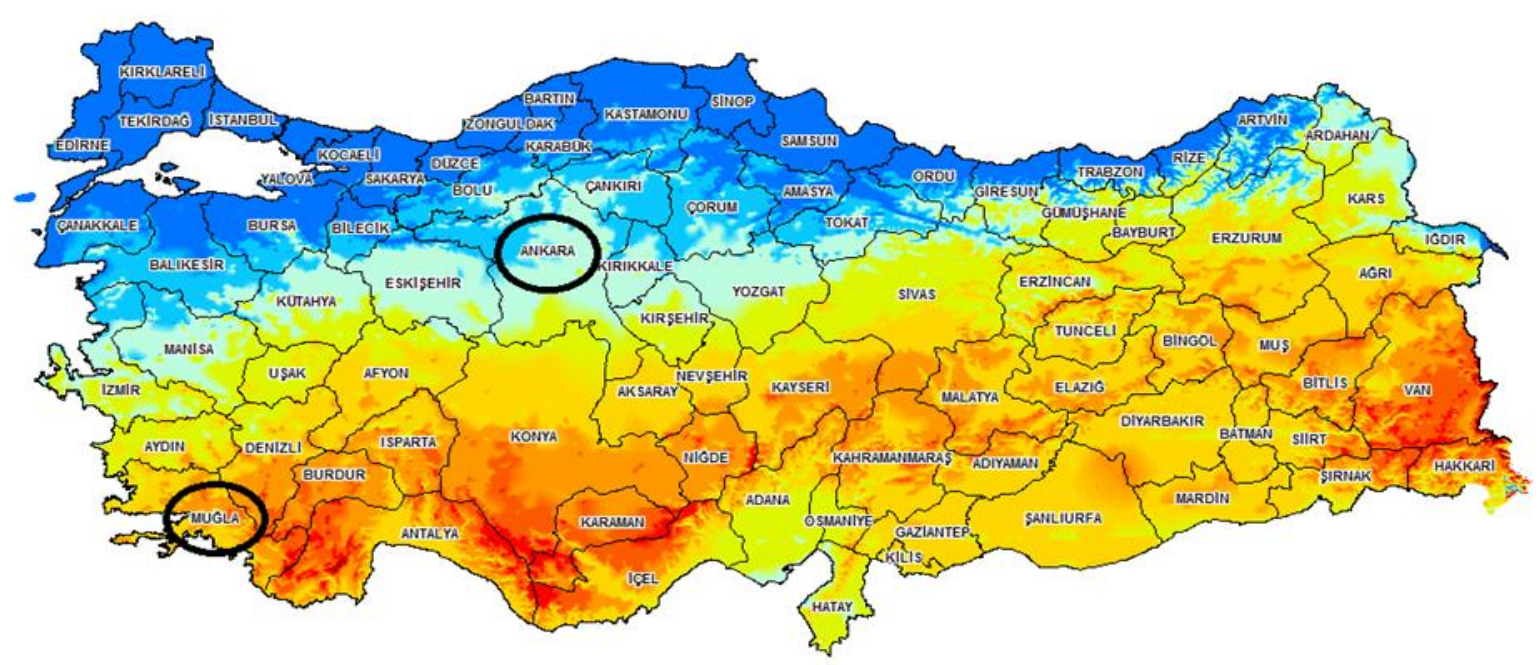

Figure. 3. Map of selected cities with insolation colours

Table 1. Some simulation inputs for defining locations

\begin{tabular}{lll}
\hline Parameters & Muğla & Ankara \\
\hline Hour and minute & 12.00 & 12.00 \\
Pressure & $930 \mathrm{mbar}$ & $870 \mathrm{mbar}$ \\
Azimuth angle & 0 & 0 \\
Longitude & $28,36 \mathrm{E}$ & $32,85 \mathrm{E}$ \\
Latitude & $37,21 \mathrm{~N}$ & $32,85 \mathrm{~N}$ \\
\hline
\end{tabular}


Seasonal variation of spectral irradiance-wavelength for the selected 2 cities on horizontal surfaces are given in Figures 4 and 5. In calculations wavelength in sun is used up to $1.5 \mu \mathrm{m}$ because $92 \%$ of total solar irradiation is under this wavelength and most solar cells spectral responses are high under this point. The amount of incoming radiation varies due to climatic differences. Four months are selected representing seasons and wavelength distribution in horizontal planes for cities with global standard spectrum at AM0 conditions are given between in Figures 6 to 9.

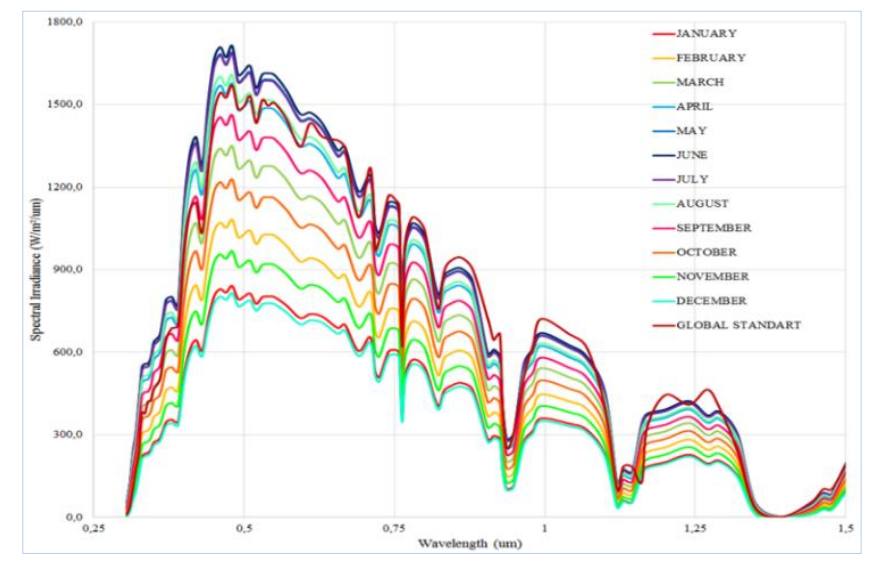

Figure 4. Horizontal surface seasonal variation of radiation for Muğla

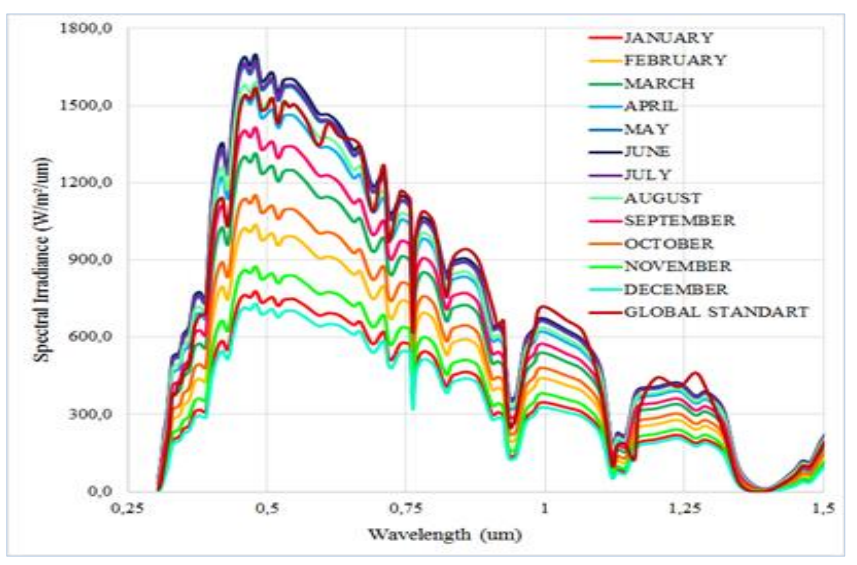

Figure 5. Seasonal variation of radiation on horizontal surface for Ankara

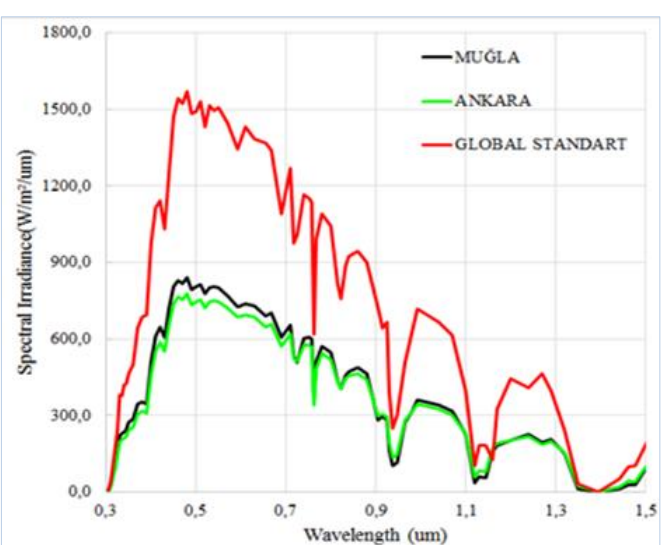

Figure 6. Spectral irradiance for horizontal surface in Mugla and Ankara in January

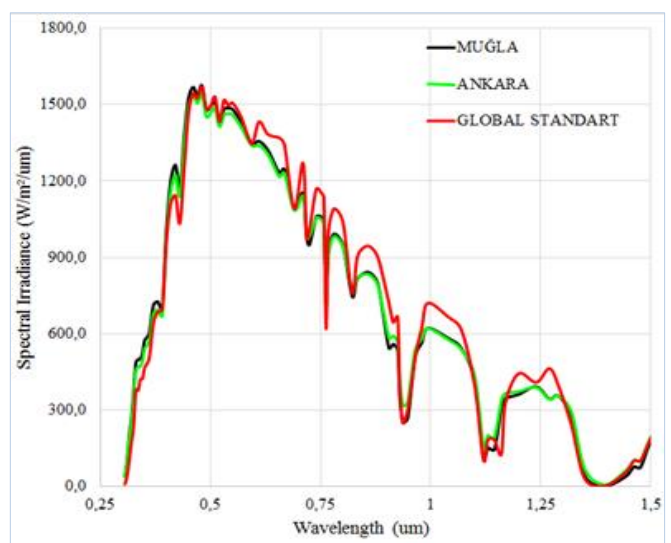

Figure 7. Spectral irradiance for horizontal surface in Mugla and Ankara in April 


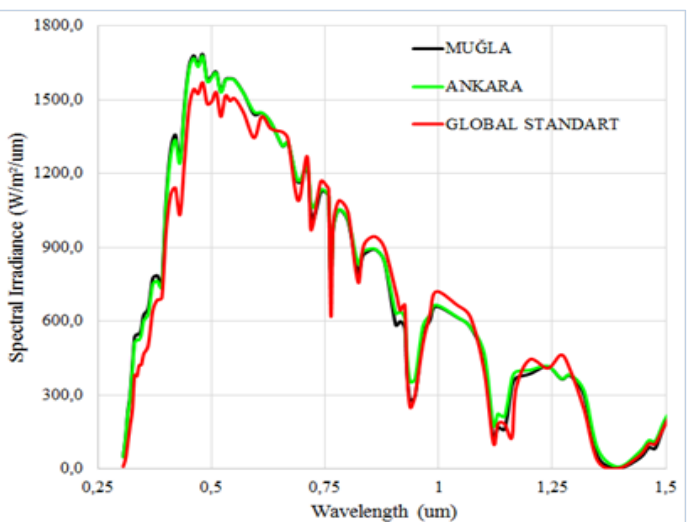

Figure 8. Spectral irradiance for horizontal surface in Mugla and Ankara in July

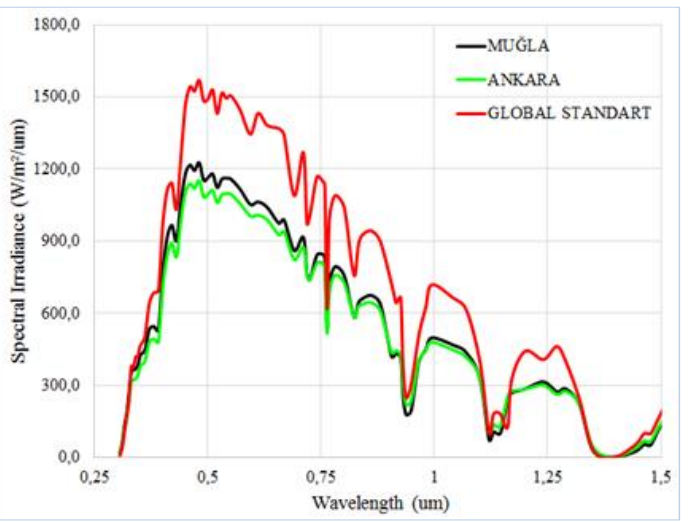

Figure. 9. Spectral irradiance for horizontal surface in Muğla and Ankara in October

Although horizontal irradiation is important for determining the solar potential and used in measurements generally plane of irradiation (POA) is very important in solar application. In photovoltaic applications PV planes are installed mostly with latitude tilts or obeying the roof slopes. In Turkey generally $30^{\circ}$ tilt roof are constructed so in the present study spectral distribution is also calculated for $30^{\circ}$ tilt surfaces and the results in seasons are given between Figures 10 to 13 .

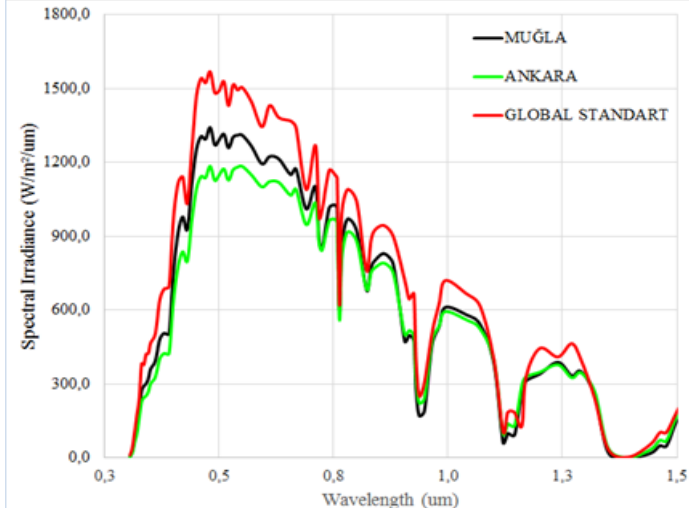

Figure 10. Spectral irradiance for $30^{\circ}$ inclined surface in Mugla and Ankara in January

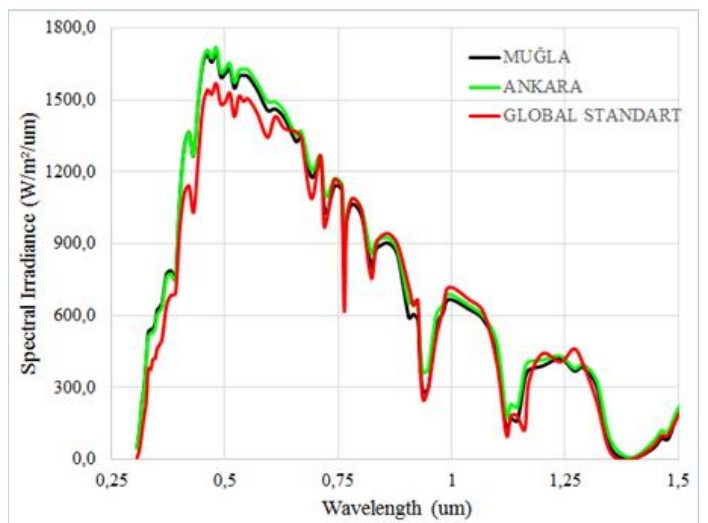

Figure 12. Spectral irradiance for $30^{\circ}$ tilt surface in Muğla and Ankara in July

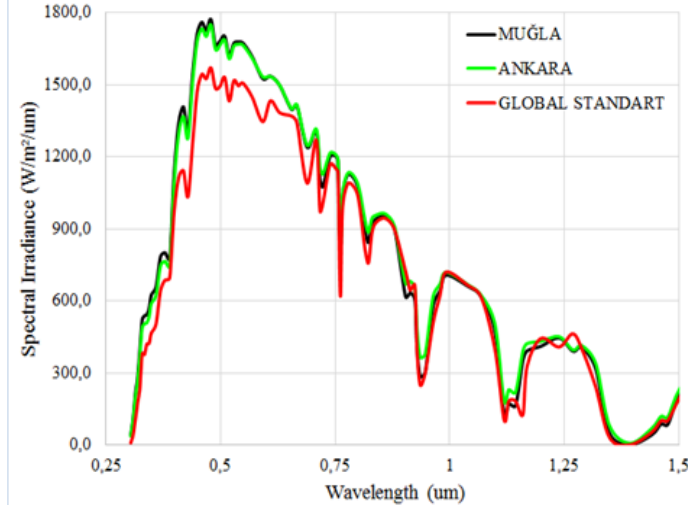

Figure 11. Spectral irradiance for $30^{\circ}$ inclined surface in Mugla and Ankara in April

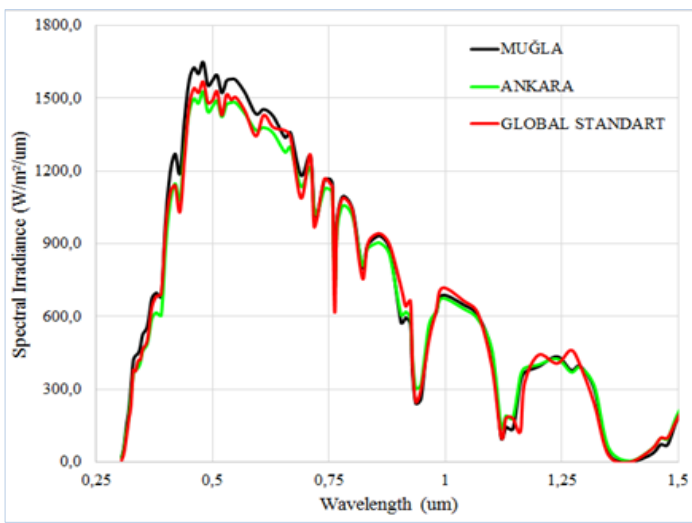

Figure 13. Spectral irradiance for $30^{\circ}$ inclined surface in Mugla and Ankara in October 


\section{RESULTS AND DISCUSSION}

Due to the different climatic and geographical characteristics of Muğla and Ankara, the amount of incoming radiation varies. Besides, the amount of incoming radiation shows differences seasonally. In particular, the amount of radiation differs due to differences in temperature, humidity and evaporation levels between seasons. The amount of radiation coming to the horizontal surface is less then compared to other seasons in winter and autumn. But in the same seasons the amount of radiation coming to the sloping surfaces are more than the amount of radiation coming to the horizontal surface. In this case, more radiation falls on the sloped surface of the module in winter and autumn. According to this result, slope can be a factor that increasing efficiency of PV modules in these seasons. The amount of radiation coming to these regions was calculated with the SPCTRL 2 program. In the SPCTRL 2 model used in calculation, it has more atmospheric effects than other models. This ensures that the results obtained are more reliable. The amount of radiation coming to the horizontal surface is less in winter and autumn than in other seasons.

\section{CONCLUSION}

The amount of solar radiation in the atmosphere can be calculated for any moment of the day with SPCTRL 2. The spectrum of the solar radiation can be seen easily calculated and PV system efficiency values for different time intervals can be understood with presented models. Most of the incident solar radiation is in the range of $0.2-1.1 \mu \mathrm{m}$ wavelength so wavelength up to $1.5 \mu \mathrm{m}$ is calculated in the present study. As the wavelength increases, the amount of radiation to the surface decreases. It is seen from the graphs that there is more radiation in spring and summer seasons than in other seasons. Moreover, it is observed that in winter and in autumn, more radiation is emitted to the inclined surface than the horizontal surface. The greatest amount of incoming radiation is in the range of $0.2-1.1 \mu \mathrm{m}$ wavelength. In this wavelength range, sudden decreases occur due to atmospheric and climatic reasons. Water vapour and gasses present in the atmosphere cause absorption and scattering at certain wavelengths of incoming radiation. This causes a sudden decrease in the amount of radiation. Ankara is a crowded city and the annual total solar radiation per square meter is $10 \%$ lower than Muğla so it is expected that PV modules output installed at Muğla will produce directly proportional to irradiation. But calculations show that (not described and given in detail at this work) decrease in some types of solar cells is not linearly changes with the decrease in incident solar radiation. But this study shows that the amount of radiation to a horizontal or inclined surface for a given day with SPCTRL 2 can be calculated based on atmospheric conditions.

\section{REFERENCES}

[1] R. Eke, T. R. Betts and R. Gottschalg, "Spectral irradiance effects on the outdoor performance of photovoltaic modules" Renewable and Sustainable Energy Rewievs, vol. 69, pp. 429-434, March 2017.

[2] Lighthouse, "The solar spectrum," PV Lighthouse, 2018. [Online]. Available at: https://www2.pvlighthouse.com.au/resources/courses/altermatt/. [Accessed: 16 Apr 2018].

[3] Are Solar, "Harness the power of the sun," Are Solar, 2012. [Online]. Available at: http://rredc.nrel.gov/solar/spectra/am1.5. [Accessed: 10 July 2012].

[4] T. R. Betts "Investigation of photovoltaic device operation under varying spectral conditions," PhD Thesis. Loughborough University, Jan. 2005.

[5] International Electro-Technical Commission, "Photovoltaicdevices-Part 7. Computation of the spectral mismatch correction for measurements of photovoltaic devices," IEC 60904-7:2019 (Ed. 3, 2008), Geneva, Switzerland, 2008.

[6] J. Polo, M. Alonso-Abella, Ruiz-Arias J. A., and Balenzategui J. L., "Worldwide analysis of spectral factors for seven photovoltaic technologies," Solar Energy, vol. 142, pp. 194-203, 2017.

[7] R. Gottschalg, T. R. Betts, D. G. Infield, and M. J. Kearney, "On the importance of considering the incident spectrum when measuring the outdoor performance of amorphous silicon photovoltaic devices," Measurement Science and Technology, vol. 15, no. 2, pp. 460-466, 2004.

[8] T. Ishii, K. Otani, T. Takashima, and Y. Xue, "Solar spectral influence on the performance of photovoltaic (PV) modules under fine weather and cloudy weather conditions," Prog Photovolt: Res Appl., vol. 21, no. 4, pp. 481-489, Nov. 2011.

[9] "Photovoltaic devices-Part 3: measurement principles for terrestrial photovoltaic (PV) solar devices with reference spectral irradiance data," IEC 60904-3:2019, 2008.

[10] A. Virtuani, H. Müllejans and E. D. Dunlop, "Comparison of indoor and outdoor performance measurements of recent commercially available solar modules," Progress in Photovoltaics Research and Application, vol. 19, no. 1, pp. 11-20, Jan. 2011.

[11] R. Gottschalg, T. R. Betts, D. G. Infield and M. J. Kearney, "The effect of spectral variations on the performance parameters of single and double junction amorphous silicon solar cells," Sol Energy Mater Sol Cells, vol. 85, no. 3, pp. 415-428, Jan. 2005. 
[12] Y. Nakada, S. Fukushige, T. Minemoto and H. Takakura, "Seasonal variation analysis of the outdoor performance of amorphous Si photovoltaic modules using the contour map," Sol Energy Mater Sol Cells, vol. 93, no. 3, pp. 334337, Mar. 2009.

[13] R. E. Bird, "A simple spectral model for direct normal and diffuse horizontal irradiance," Solar Energy, vol. 32, no. 4, pp. 461-471, 1984.

[14] F. Kasten, "A new table and approximate formula for relative optical air mass," Arch. Meteorol. Geophys. Biochlimatole., vol. 14, pp. 206-223, 1966.

[15] E. P. Shettle and R. W. Fenn, "Models of the atmospheric aerosol and their optical properties," Advisory Group for Aerospace Reseach and Development, 1975.

[16] A. Angstrom, "Technique of determining the turbidity of the atmosphere," Tellus, vol. 13, no. 2, pp. 214-231, May 1961.

[17] M. D. King and B. M. Herman, "Determination of the ground albedo and the index of absorption of atmospheric. particulates by remote sensing-Part 1: Theory," Journal of the Atmospheric Science., vol. 36, no. 1, pp. 163-173, 1979.

[18] T. K. Van Heuklon, "Estimating atmospheric ozone for solar radiation models," Solar Energy, vol. 22, pp. 63-68, 1979.

[19] R. E. Bird, "Terrestrial solar spectral modeling," Solar Cells, vol. 7, p. 107, 1983.

[20] C. F. Becker and J. S. Boyd, "Solar radiation availability on surfaces in the united states affected by season, orientation, latitude, altitude, and cloudiness," Solar Energy, vol. 1, no. 1, pp. 12-31, Jan. 1957.

[21] R. C. Temps and K. L. Coulson, "Solar radiation incident upon slopes of different orientations," Solar Energy, vol. 19, no. 2, pp. 179-184, 1977.

[22] R. E. Bird and R. L. Hulstrom, "Precipitable water measurements with sun photometers," J. Applied Met., vol. 21, pp. 1196-1201, 1982

[23] B. Leckner, "The spectral distribution of solar radiation at the earth's surface--elements of a model," Solar Energy, vol. 20, no. 2, pp. 143-150, 1978.

[24] D. T. Brine and M. Iqbal, "Solar spectral diffuse irradiance under cloudless skies," Solar Energy, vol. 30, pp. 447$453,1983$.

[25] C. G. Justus and M. V. Paris, "A model for solar spectral irradiance at the bottom and top of a cloudless atmosphere," J. of Climate and Applied Meteorology, vol. 24, no. 3, pp. 193-205, 1985.

[26] J. E. Hay and J. A. Davies, "Calculation of the solar radiation incident on an inclined surface," Proceedings, First Canadian Solar Radiation Data Workshop, 1978.

[27] M. Iqbal, "An introduction to solar radiation," New York: Academic Press, 1983.

[28] H. Neckel and D. Labs, "Improved data of solar spectral irradiance from 0.33 to $1.25 \mu$," Solar Phys., vol. 74, pp. 231-249, 1981.

\section{BIOGRAPHIES OF AUTHORS}

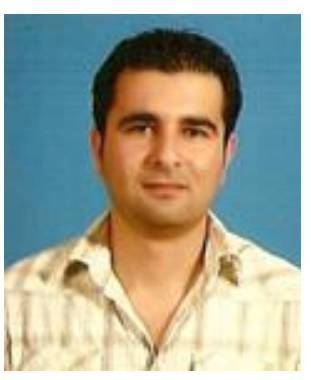

Murat Kabakci received the B.Sc. degree in physics education from the University of Muğla Sitkı Koçman, Mugla, Turkey, in 2009. The MSc degree in physics from the University of Mugla, Turkey, in 2013 and continue his PhD in institute of Science from the University of Mugla, İzmir Turkey. He is also received the B.Sc. degree in math education from the University of Muğla Sitkı Koçman, Mugla, Turkey, in 2010.

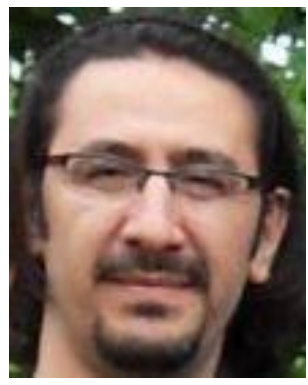

Rustu Eke received the B.Sc. degree in physics education from the University of Ondokuz Mayıs, Amasya, Turkey, in 1997. The MSc degree in physics from the University of Mugla, Turkey, in 2000 and completed his PhD in institute of Solar Energy from the University of Ege, İzmir Turkey, in 2007. He is currently studying as an Associated Professor in Department of Physics of Mugla Sitk1 Kocman University, Turkey. He is studying on photovoltaics and renewable energy sources. 